\title{
Selected Reference Books of 1998
}

\author{
Eileen Mcllvaine
}

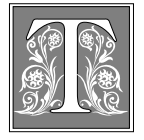

his article follows the pattern set by the semiannual series initiated by the late Constance

M. Winchell more than fifty years ago and continued by Eugene P. Sheehy. Because the purpose of the list is to present a selection of recent scholarly and general works of interest to reference workers in university libraries, it does not pretend to be either well balanced or comprehensive. A brief roundup of new editions of standard works is provided at the end of the articles. Code numbers such as AD124 and DB13 have been used to refer to titles in the Guide to Reference Books, $11^{\text {th }}$ ed. (Chicago: ALA, 1996).

\section{Periodicals and Newspapers}

The Waterloo Directory of English Newspapers and Periodicals, 1800-1900. Ed. John S. North. Waterloo, Ont.: North Waterloo Academic Pr., 1997. 10 vols. 7349 p. il, facsims, ports. $\$ 3,645$ (ISBN 0-921075-18-9).

This indispensable set has a complicated publishing history. The Waterloo Directory of Victorian Periodicals, 1824-1900 (which includes England, Scotland, and Ireland) was published as a single volume in 1976 (Guide AD114). That volume is now being updated and greatly expanded along with the revised directories of Irish and Scottish newspapers and periodicals published in 1986 (Guide AD124) and 1989 (Guide AD119), respectively. A CD-ROM version of the present title was issued in 1994. This print version adds some 2,000 titles and updates about half the entries. This is Series One of a projected five; each series will supersede the earlier, incorporating all of the information (and corrections). The compilers felt, realistically, that if they are unable to complete the whole set for some reason, at least some information will be available.

This first series is an alphabetical list of some 25,000 newspapers and journals in all fields, although the emphasis is on art and architecture, children's magazines, theater, humor, music, and women. Of the 25,000 titles, an astonishing 8,000 were examined in detail. Many of the others were found cited, but not located; they were included because the editor hopes "to provide an introduction to the field, rather than limit the research in some tidy way" (p.10).

The bibliography excludes government publications and company reports but does include transportation schedules, almanacs, and town directories, as well as the more traditional journals and newspapers published at least once a year. When the set is complete, the editors hope to have covered in fifty volumes some 125,000 serials published in England between January 1, 1800, and December 31, 1900, even if most of the issues appeared before or after those dates.

The information provided for each title varies, of course, sometimes just being limited to a title and date. But when possible, the title, variant titles, dates, place of publication, editor, contributors, circu-

Eileen McIlvaine is Head of Reference and Collections in Butler Library at Columbia University; e-mail: mcilvain@columbia.edu. Although it appears under a byline, this list is a project of the reference departments of Columbia University Libraries, and notes are signed with the initials of one of the following staff members: Barbara Sykes-Austin, Avery Library; Mary Cargill, Anice Mills, Robert H. Scott, Junko Stuveras, Sarah Spurgin Witte, Butler Library; Deborah Wassertzug, Journalism Librarian; Olha della Cava, Lehman Library; Elizabeth Davis, Music Library; Nancy E. Friedland, Undergraduate Library. 
lation, and selected British locations are listed. There are indexes of issuing bodies, places and people, and subjects. The 5,000 reproductions of title pages make it fascinating to browse.

Not all the information seems to be complete. The notorious Tit-Bits, for example, which was published for many years, lists only one date. So I can hope that Tootsie Sloper: A Journal of Brightness, Lightness and Frivolity had more than one issue. And this monumental achievement does shed brightness and lightness, and indeed frivolity on the nineteenth century.-M.C.

\section{Philosophy}

Routledge Encyclopedia of Philosophy.

Ed. Edward Craig. London:

Routledge, 1998. 10 vols. \$2,995 (ISBN

0-415073103). LC 97-4549.

This is the first major encyclopedia of philosophy in English since Macmillan's Encyclopedia of Philosophy (1967, suppl. 1996. Guide BB24). The ten-volume set covers world philosophy from antiquity to the twentieth century. Volume 10 furnishes an extensive index that brings together related articles. For example, under "medical ethics," volume and pages of the main article are indicated in bold characters followed by related articles in other volumes from "doctor/patient relationship" to the "Tuskegee project." If you look up a country, entries on philosophers of the country are listed alphabetically along with some topics important to the country's history of philosophy.

In addition to individual philosophers, schools and "isms," the work treats world philosophy from both the historical perspective and the geographic. It succeeds in bringing some organic unity to the diversity. The articles were contributed by some 1,300 philosophers worldwide, and each article is accompanied by a bibliography of reference and further reading. Many university and research libraries will not be ready to trade their worn copies of the MacMillan Encyclopedia for this new version, but this is a worthwhile addition to their collections
The set comes with a CD-ROM disc. The Windows-based database requires $133 \mathrm{MHz}$ Pentium processor and $16 \mathrm{MB}$ of RAM. Although the installation guide recommends $9 \mathrm{MB}$ of available hard disk space, in the actual installation $15 \mathrm{MB}$ or more is necessary, even for the browseronly installation. The database typically shows three windows on the screen: index or table of contents, text, and bibliography. The DynaText-based database is fairly easy to navigate and better than those textual databases using the Acrobat Reader.-J.S.

\section{Literature}

Reference Guide to Russian Literature.

Ed. Neil Cornwell; assoc. ed. Nicole Christian. London, Chicago: Fitzroy Dearborn, 1998. xl, 972p. \$135 (ISBN 1-8849-6410-9). LC 97-169924.

Despite the existence of a number of valuable English-language reference tools for the study of Russian literature, such as the Handbook of Russian Literature, ed. Victor Terras (1985. Guide BE1411), Wolfgang Kasack's Dictionary of Russian Literature since 1917 (1988. Guide BE1412), or the ongoing Modern Encyclopedia of East Slavic, Baltic and Eurasian Literatures (Gulf Breeze, Fla.: Academic Intl., 1977- ), this volume represents an important new contribution that most libraries with serious coverage of Russian and comparative literature will want to acquire.

One in a series of reference handbooks produced by this relatively new publishing company, the Guide is the collective endeavor of a large team of British, American, and Russian specialists. Its approach differs somewhat from that of its predecessors in its special focus on individual works of literature, including brief summaries of plot and theme and discussion of the major issues of interpretation and analysis.

The book opens with a series of wellwritten essays surveying the major periods, genres, schools of criticism, and so forth. In the main body of text that follows, major authors (as well as key anonymous works) are surveyed, from 
the Old Russian period to the present. Each article begins with a concise biographical sketch, a bibliography of the key editions and translations as well as critical works, and then, typically, an overall characterization of the author's work followed by two- or three-page discussions of major works. Alphabetical and chronological tables of contents, along with a title index, provide varied means of access to the contents.

The work lends itself to quick lookups for those wishing to familiarize themselves with a particular author or work but also admirably serves the needs of those seeking to obtain quickly an overview of the major themes and issues of Russian literature, to identify potential areas for further research, or to fill gaps in a specialist's knowledge of the field. It is not only a work that many libraries will find essential for the collections, but it is something that many individual scholars will want to acquire for their personal reference collections as well.-R.H.S.

\section{Film and Radio}

Dunning, John. On the Air: The Encyclopedia of Old-Time Radio. New York: Oxford Univ. Pr., 1998. 822p. \$55 (ISBN 019-507678-8). LC 96-41959.

\section{Historical Dictionary of American Radio}

Eds. Donald G. Godfrey and Frederic A. Leigh. Westport, Conn.: Greenwood, 1998. 485p. $\$ 89.50$ (ISBN 0-31329636-7). LC 97-33140.

These two well-researched, comprehensive volumes complement each other nicely. In On the Air, John Dunning has updated, revised, and enlarged his earlier encyclopedia Tune in Yesterday (Guide BH308), published in 1976. Correcting oversights and adding new material that includes "full descriptive and factual details on hundreds of people and shows not covered in the first book" (Introd.), Dunning has produced an informative, carefully researched work. Alphabetical entries describe individual radio shows and significant radio personalities. Each entry provides a program's brief broadcast history and detailed listings of casts, announcers, writers, directors, theme songs, etc., followed by narrative essays that cover the history and memorable features of the show. A program's current availability on cassette tape is often noted. Cross-references and an index that denotes main entries in boldface help the reader identify individuals and program titles. Students of radio broadcasting will also benefit from the extensive bibliography, divided into books; newspapers and periodicals; logs; and miscellaneous items such as publicity releases and bound scripts.

The Historical Dictionary of American Radio, although equally thorough, takes a slightly different approach. Beginning with an introductory essay that gives a brief history of the medium followed by a chronology of significant events from 1837 to 1997 , this volume covers the broader political, economic, and social aspects of radio, with less emphasis on programs and personalities. Entries encompass technical and business terminology, formats, and descriptions of government agencies, regulations, and policies that have affected radio. Concise, clear coverage of the FCC's role with respect to regulatory control, licensing, censorship, and deregulation is especially noteworthy. Each entry, arranged alphabetically, is signed. Brief biographies of the hundred or so contributors, all professors in the field of mass communications or broadcast journalism, are included at the back of the volume. Cross-references and an index with main entries noted in boldface are valuable aids. The Select Bibliography includes books, journal articles, theses, government documents, and a list of about seventy relevant Web sites ranging from the Bellingham Antique Radio Museum to the Telecommunications Act of 1996.

Both of these volumes are notable for their attention to detail and their scholarly approach to this burgeoning area of study.-A.M.

Langman, Larry. The Media in the Movies: A Catalog of American Journalism Films, 1900-1996. Jefferson, N.C.: McFarland, 
1998. 333p. il. \$65 (ISBN 0-7864-0433-

7). LC 97-46949.

The latest offering form Larry Langman, author of a number of esteemed film reference works, is a compilation of film summaries for more than a thousand features and serials released between 1900 and 1996 that have as their central concern journalism in its different guises, both print and broadcast. The work is intended for researchers seeking to trace the film depiction of journalism and journalists and particularly how journalists interact with their news stories and the public. It also is intended to reflect the way these filmic depictions have changed over nine decades.

The book opens with a brief filmographic essay that betrays a heavy bias toward films from the earlier part of the century (primarily before 1960), with later films given only passing mention. The ten stills and posters reproduced in the work also give evidence of the author's emphasis on films made before 1960.

The film listings offer brief synopses and analyses of the films, which are listed alphabetically and given entry numbers that are used in the personal name index that follows. Listings include the title and release date of the work with studio names abbreviated. The credits show director, screenwriter, and principal actors but do not include the names of the characters the actors play. In addition, the book's appendixes belie its title because they cover newspaper film series and serials and peripheral newspaper films; these lists do not include titles that cover broadcast media. A bibliography at the back of the volume lists supplementary readings related to journalism, but not to films per se.

Because the criteria for inclusion in this obviously selective work are never discussed, the reader may be left wondering why it is lean on films made after 1960 and why, of those films, titles such as Network and To Die For are omitted but the questionable Dead Men Don't Die is included.
Given Langman's reputation as a filmographer, libraries with an extensive film collection should purchase this title. But also note the publication in 1997 of a similar work entitled From Headline Hunter to Superman: A Journalism Filmography by Richard Ness, an instructor at Wayne State University's communications department and researcher in the journalism film genre (Lanham, Md.: Scarecrow, 1997.789p. \$89.50). That work, despite its numerous typographical errors, has an international scope, lists its films chronologically, has fuller credits and cast listings, and, most important, covers more than 2,100 films, including made-for-TV movies.-D.W.

\section{Art and Architecture}

Ballast, David Kent. The Encyclopedia of Associations and Information Sources for Architects, Designers and Engineers. Armonk, N.Y.: Sharpe Professional, 1998. 814p. \$125 (ISBN 0-7656-0035-8). LC 97-20300.

Despite its title, this is not an encyclopedia but, rather, a compilation of directories relevant to those professions named in the title. This work will indeed be useful to architects, designers, engineers, and students of those disciplines if care is taken to remember that information delivery systems are in a rapidly expanding and transformative period. Online databases and CD-ROMs change their formats only slightly less frequently than Web sites, and any directory is likely to have some of its contents superseded before it is even published.

Still, there is an impressive range of coverage in many of the twelve sections. The 534 entries for associations and organizations include the standard address (including e-mail and Web address) and descriptive information and find groups such as the American Jail Association and the ALA sharing a page. Two sections are given over to journals and newsletters, their publishers, frequency, and prices, which can be useful as a selection tool for librarians, as will the sections on online databases (89 are listed), CD-ROMs (103), 
and Web sites (546). However, some sections are of questionable value; for example, the resources of associations (i.e., publication lists) are incomplete and likely to go out of date almost immediately, and keywords separate from the keyword index are redundant. Moreover, there are factual errors: a quick scanning of the journal titles and the indexes that cover them revealed at least ten titles indexed by the Avery Index to Architectural Periodicals (Guide BF209), but not listed as such, which does a disservice to users as well as providers.

The strength of this resource lies in its organizational listings, which include government agencies, research and testing laboratories, its wide scope of printed membership directories and database listings (everything form the American Society of Plumbing Engineers to the Union List of Artists Names), and its successful efforts to include such a wide variety of professional services in its pages.-B.S-A.

\section{Encyclopedia of Comparative Iconogra-} phy: Themes Depicted in Works of Art. Ed. Helene E. Roberts. Chicago: Fitzroy Dearborn, 1998. 2 vols. 1120p. il. \$250 (ISBN 1-57958-009-2). LC 98163033.

In her introduction to this two-volume work on major themes prevalent in works of art, editor Helene Roberts makes an important practical point: "Without a knowledge of the many narratives from mythology, religion and literature that animate the world's art, much of that art is closed to modern interpretation and understanding" (paraphrased from $p$. vii). Roberts and her forty-one contributors have provided a useful means to access the messages underlying the images, folktales, plays, fables, myths, poetry, and other forms of artistic representation that cross many culture and centuries.

The main part of the encyclopedia consists of an alphabetical list of approximately 120 broad themes, such as abandonment, madness, witchcraft, melancholy, etc. Each of these essays discusses a selected group of narratives illustrative of the topic: Oedipus, Moses, and foundling hospitals are among the major narratives found in the essay on abandonment for example. A list of selected works of art and further readings completes the entry.

In addition, there are seven indexes that enable the reader to find specific mythological, historical, and Judeo-Christian personages, places, and concepts referenced to the Bible, the Koran, and other religious texts, non-Western cultures, religions and mythologies, artists, authors, composers, filmmakers, and literary texts, and a subject index (called "Other Names and Terms"), all of which refer back to the essays. Illustrations are limited to one fullpage black-and-white image per essay.

This is a refreshing approach to a subject that is often presented in a single alphabet, without the benefit of the thematic arrangement that will satisfy the contextual requirements essential to iconographic interpretation and understanding. A general reading list in the first volume extends to six double-columned pages and is not duplicated in the readings cited in each chapter.

The Roberts encyclopedia aims to distinguish itself from this thicket of sources by using a comparative method to describe the use of iconography in art and to organize itself from the point of view of the actions, situations, and concepts that have been selected for the essays ( $p$. viii). In so doing, it recommends itself as a first step when beginning an iconographic search, in the knowledge that any further steps can be traced through the reading list and the works of art. This latter feature is especially welcome but could have been better exploited if there had been a key devised from the list of artworks to the bibliographic sources in which it is expected they can be found.B.S-A.

GATF Encyclopedia of Graphic Communications. Eds. Richard M. and Frank J. Romano. Upper Saddle River, N.J.: Prentice-Hall, 1998. xxxviii, 945p. il. \$350 (ISBN 0-13-096422-0). LC 98008329. 
GATF, the Graphic Arts Technical Foundation, has long been active in providing information to professionals in the graphic communications industries through publications, seminars, and electronic media. With publication of the GATF Encyclopedia of Graphic Communications, GATF has broadened its audience with information useful to a more general public without neglecting the specialist. This is a wonderful work with comprehensible entries on just about everything related to graphic communications.

The opening essay entitled, "The Story of Print: The First 500 Years," provides a useful overview. The main body of the encyclopedia consists of 10,000 terms and more than 650 illustrations related to every aspect of visual communications: print to desktop publishing, photography, computers and networking, and more. Entries include technical terms, components, processes, equipment related to visual communications, and biographical entries for those individuals who contributed to the development of visual communications through invention. Nice additions include the history of the alphabet and a 16-page color insert on the color spectrum and color reproduction.

The well-written and concise entries are arranged alphabetically and are extensively cross-referenced by bolded terms. Most of the entries are a few lines; however, broader topics such as print, photography, and type and typography receive fuller treatment. Generally, entries for broader topics will include a history of the topic followed by information that relates to the medium in a professional setting. For example, the section on type and typography begins with a history of type through desktop publishing followed by information on characters of type and letter elements such as serif and sans serif and how they were used in the industry. A time line of communications history and a bibliography follow the main body.

This work is useful for professionals involved in publishing, printing, or graphic arts and for the general public with interest in any aspect of visual communications. Highly recommended.-N.E.F.

Maliszewski-Pickart, Margaret. Architecture and Ornament: An Illustrated Dictionary. Jefferson, N.C.: McFarland, 1998. 198p. il. \$35 (ISBN 0-7864-03837). LC 97-33112.

The perennial complaint about dictionaries is that one has to know how a word is spelled in order to look it up. The same holds true with dictionaries of architecture; for example, to find out what the space surrounding an arch is called or what terms differentiate among various masonry bonding patterns, one often ignores the alphabetical arrangement of entries and, instead, flips through a dictionary in the hope of seeing the desired architectural form or diagram revealed in the illustrations.

This small, but useful, volume acts as a kind of reverse dictionary to the mostoften-used standard sources, such as those by Cyril M. Harris, for example, his Dictionary of Architecture and Construction (2d ed. 1993. Guide BF242), Historic Architecture Sourcebook (1977, and its reprint title, Illustrated Dictionary of Historic Architecture, 1983. Guide BF245). It presents labeled drawings and photographs of building components and architectural elements in broad categories, such as windows and doors, walls, roofs, columns, stairs, ornament and moldings, arches, vaults, and domes so that, turning to the walls section, one has only to look at the illustrations in that section (grouped many or one to a page depending on the nature of the structure) to find brick and stone bonding patterns named and comparatively illustrated, or at the section on arches to see a spandrel identified in situ. Actual definitions follow in a single dictionary section where the terms are arranged alphabetically.

The ornament and moldings section presents a variety of patterns and theme variations, making it useful to designers who wish to select a motif in addition to being able to identify one known already. 
Finally an appendix, "Describing Architecture," gives examples of various building types in narrative form that encompass a recommended checklist of points necessary to describe a building accurately. A bibliography follows.

This book will be useful to architects, historians, preservationists, students, and interested lay public to identify, as well as to learn, architectural terms used primarily in the context of American architecture and its historical forms.-B. S-A.

\section{Music}

Temperley, Nicholas. The Hymn Tune Index: A Census of English-Language Hymn Tunes in Printed Sources from 1535 to 1820. Oxford: Clarendon Pr., 1998. 4 vols. \$550 (ISBN 0-19-311150-0). LC $97-$ 25758.

This work aims to present a scholarly organization and treatment of hymns, as well as to provide a practical means of accessing information about them in a variety of ways. Its subject is British and American hymns and metrical psalm tunes published before 1820 .

A four-volume work, the tune census comprises volumes three and four with entries for 17,424 tunes. Each entry contains a tune number (assigned in numeric sequence), the tune coded in alpha/numeric form for identification, the tune meter, the keys in which the tune has been published, and a tune-setting code. This last code indicates the number of voices for which the tune has been written and the placement of the voice that carries the tune and thus serves as the basis for the coding. In addition to these musical attributes, each entry contains the author's or editor's name, any additional author or editor source attribution, the code for the text incipit, the tune's name or heading by which it is known, the year of publication, and a letter code indicating the country or region of publication. For any of this information, italic type is used if information is not taken from the item, but is being supplied by the author.

To access the information in the census entries, a number of indexes are pro- vided in volume two. The "Index of Tunes by Musical Incipit" contains the coded tunes listed in order by numeric code. Using this index requires the ability to hum or sing the tune's pitches and to establish a pitch center (identified as " 1 "). Every other pitch is then coded into numbers relative to the distance from " 1. ." The "Index of Tunes by Name" points to an entry in the tune index, but if the same name has been given to more than one tune, the coded tune Incipit for each entry is given to facilitate identification. The "Index of Tunes by Composer" contains the last names of the composers or editors and refers to entry numbers, as do entries in the "Index of Tunes by Text Incipit." The last index contains codes listed in alphabetic order, the letters of which are formed from the first letters of each word in the first line of text (e.g., OMSWMT = "O my soul, what means this sadness"). "Tunes for Unusual Text Metres" (the most common being lines with 8 or 6 beats, or combination thereof) completes the indexes.

Volume One provides the scholarly apparatus detailing the state of research in the field, historical and technical introductions, and a bibliography of sources. A concordance to three standard hymn collections is provided. Despite the challenging appearances of many of the codes resulting from their machine-readable source, this volume will meet the information needs in the area of hymn identification and study.-E.D.

\section{Political Science}

Burg, David F. Encyclopedia of Student and Youth Movements. New York: Facts on File, 1998. 254p. il. \$50 (ISBN 0-81603375-7). LC 97-32408.

This informative, if selective, encyclopedia provides an overview of international youth movements and student groups from the Middle Ages to the present day. Rather than an exhaustive approach, the author acknowledges that he has necessarily had to exclude more than he has included. His aim has been to describe groups that "represent the most signifi- 
cant of those movements and events, while also revealing their diversity" (Pref.).

Arranged alphabetically, the brief, clearly written entries include movements, groups, and significant individuals as diverse as Joan of Arc and Abbie Hoffman. Cross-references to related topics as well as bibliographic sources at the end of some entries are useful aids. Blackand-white photographs throughout the text both amplify and illustrate the protests and events being described. An extensive bibliography at the end of the volume provides sources for further study. Although the index is useful for locating a specific group or individual, it lacks geographic access points that would list youth movements and groups by country.

Though it might have been more comprehensive in its coverage, especially of the extent of involvement of American students in protests of the late 1960s, this well-researched encyclopedia will be for value to undergraduates and others studying student movements and their impact on political, social, and cultural development.-A.M.

\section{A Historical Guide to the U.S. Govern-}

ment. Ed. George Kurian. New York: Oxford Univ. Pr., 1998. 741p. il. \$75 (ISBN 0-19-510230-4). LC 97-47442.

This encyclopedia is "a composite profile of the U.S. government through a history of the various departments and agencies that constitute it" (Pref.). It has four- to five-page signed articles on general topics, each with a fairly substantial bibliography ("Civil Service," "Statistical Information," etc.), as well as specific agencies. The preface states that the editor did not include the judiciary branch, but important court decisions are sometimes cited in the bibliographies and there is an entry on the "Supreme Court Decisions on the Presidency," though not on the Supreme Court itself.

The volume includes a convenient appendix of some of the basic documents relating to government administration, such as the Hatch Act and the Freedom of Information Act. There is a detailed and useful index.

Despite its title, it does not have the historical scope of Government Agencies, compiled by Donald R. Whitnah (1983. Guide CJ120). There are no separate entries for the Children's Bureau, the Job Corps, or the Works Progress Administration (all included in the earlier book), though there are scattered references to these agencies in the index. The bibliographies in the newer volume are fuller, but the Greenwood volume occasionally lists primary sources. Any library supporting programs in American history will need both volumes.-M.C.

\section{Women's Studies}

Amico, Eleanor B. Reader's Guide to Women's Studies. Chicago: Fitzroy Dearborn, 1998. 732p. \$125 (ISBN 1-8849657-7). LC 98-138939.

This is an excellent starting point for feminist research. Some 500 topics are addressed, including individuals, historical events, social movements, feminist theory, and general topics of current interest. Each entry provides a list of recommended books, followed by a discussion of the relative merits of each work. The entries are well written and long enough to provide useful information. Although this work is clearly intended for the generalist or beginning researcher and cites only books in English, it will be indispensable in all reference collections.

Entries are arranged alphabetically (Aboriginal Women to Zaharias, Mildred "Babe" Didrikson). A thematic list groups topics into categories (e.g., Amazons, Ancient Classical World, Ancient Near East, Hatshepsut, Prehistory, Huntinggathering cultures, Hypatia and early philosophers, Matriarchal theory, Sappho), and there is a subject index.

The Reader's Guide to Women's Studies is highly recommended. We look forward to an update.-S.S.W.

Kimball, Michelle R., and Barbara R. von Schlegell. Muslim Women through- 
out the World: A Bibliography. Boulder, London: Lynne Rienner, 1997.307p. il. \$75 (ISBN 1-55587-680-3). LC 96-25718. This is a disappointing bibliography on a subject for which there is considerable interest and demand. The bulk of the bibliography (some 2,905 citations) is arranged alphabetically by author with no annotations. It focuses primarily on "scholarly studies in English written in this century through 1995, with some works of fiction, early travel accounts, popular publications and works written by practicing Muslims which would be called 'devotional'" (Pref.). There is a small section (53 citations) of recommended books and articles.

The author arrangement would be fine if there were an adequate index, but the index is seriously flawed. Many articles are not listed in the subject index at all. For example, "Women and Shi'ism in Iran" by Mina Modares ( $m / f 5-6: 61-8)$ was not listed under Shi'ism, Iran, or Women. Articles that have been indexed are almost as difficult to find. For example, Marchia Hermansen's "The Female Hero in the Islamic Religious Tradition" (Annual Review of Women in World Religions 2:111-43) does not appear under either religion, hero, or heroine but, instead, under Islam-the female hero in (filing alphabetically after " $t$ " for "the"). It appears that most of the indexing is based on words in the title of the article, rather than upon any sort of understanding of the subject of the book or article. This kind of sloppy indexing is inexcusable at a time when we turn to printed bibliographies for the sort of access we cannot get from online sources. The Index Islamicus, Women's Resources International, and KVINNSAM all provide better access and indexing of materials relating to Islamic women. This bibliography is useful for verification of older material (when you have the author's name) and does provide adequate subject access for most articles. However, the danger is that a reader might assume comprehensive coverage and not search the other sources.S.S.W.
Women in the Third World: An Encyclopedia of Contemporary Issues. Ed. Nelly P. Stromquist. New York: Garland, 1998. 683p. Garland Reference Library of Social Science, 760. \$135 (ISBN 0-815301502). LC 98-14689.

The editor and contributors of Women in the Third World set for themselves the task of providing a feminist perspective on issues dealing with socioeconomic development in third-world countries. Specifically, they wanted to gather in one volume relevant information on existing, as well as emerging, issues pertaining to women in the developing countries and to bring a cross-disciplinary approach to the study of these issues.

The more than sixty articles in the encyclopedia are grouped into ten sections. One section deals with conceptual and theoretical issues; several sections document the situation of women in political, legal, demographic, social, and economic contexts; and still others deal with women and the environment, to explore topics that prepare for and promote change. Geographical entries comprise the last section. The essays within the sections present up-to-date information, within a feminist framework, on both traditional and well-identified issues, as well as on emerging issues such as domestic and sexual violence, creation of womenfriendly cities, AIDS, and the gender consequences of ecological deterioration and of war.

All essays follow a set of uniform parameters, but because the authors come from both the First and the Third Worlds and were drawn not only from the ranks of established scholars, but also include well-known activists and new figures in feminist literature, there are variations in approach and presentation. Thus, entries run the gamut from syntheses of the literature, to interpretations of current events, to advocacy of special issues. Quality was safeguarded through a rigorous process of peer review. The content is enriched with bibliographies, charts, and statistics. There are an annotated bibliography for the entire encyclopedia, an 
index, and several appendixes containing the texts of several key instruments of importance to women.

This is a work of high quality and broad scope, but it is more than an exercise in meticulous fact-gathering and good organization. The work is a commitment to the cause of women, for the ultimate goal of the compilers was to promote an understanding of the condition of women across different settings and countries, to underscore the pervasive reach of gender ideology, to demonstrate the relation between gender and power, and to provide insights that might lead to a proper conceptualization, and eventual solution, of the problems encountered by women in the Third World.-O.dC.

\section{History}

Reader's Guide to American History. Ed.

Peter J. Parish. London, Chicago:

Fitzroy Dearborn, 1997. 880p. \$103

(ISBN 1-884964-22-2). LC 98-101338.

Reference librarians are familiar with the scene: a student comes to the desk wanting a general work on some aspect of American history. The choice has usually been to show him hundreds and hundreds of titles under United States-History or the outdated Harvard Guide to American History (Guide DB13). The recent Guide to Historical Literature, sponsored by the American Historical Association (Mary Beth Norton, editor. New York: Oxford Univ. Pr., 1995. 2v), has helped but is too general to be useful in many cases. The Reader's Guide to American History should offer relief.

It is an encyclopedia analyzing the most significant books written on some 600 topics in American history. It includes events, individuals, and themes (though I was surprised to find no entry on the Frontier Thesis) concentrating on political, social, and economic history. It should be useful to both the beginning history student trying, for instance, to negotiate through the vast number of books written on the Civil War and the more advanced student starting research on a specific topic.
This volume does not, and does not pretend to, offer one-stop shopping. It does not list reference works, primary sources, or, for the most part, periodical articles. But it does offer an invaluable service by summarizing and evaluating the major works in American history clearly and understandably.-M.C.

\section{New Editions and Supplements}

Il Vocabolario Treccani (Roma: Istituto della Enciclopedia italiana, Fondata da Giovanni Trecanni, 1997. 5v. and CDROM disc and Guide. L2289000) is the revised and enlarged edition of Il Vocabolario della Lingua Italiana (1987. Guide AC527). Now including 160,000 entries for words accompanied by hundreds of illustrations, the emphasis is on living language and the dictionary actively adds new words and meanings. The dictionary is not meant to double as an encyclopedia, and proper names of people are excluded unless they have become part of common vocabulary. A typical entry is composed of part of speech, word origin, sample conjugation for a verb, meanings of the word, and examples of usage, which are often quotations from classic authors such as Manzoni and Ariosto. The dictionary is visually appealing offering beautiful plates, excellent drawings and the $C$. Plantin typeface for the text. The set includes a CD disc that offers the possibility of compiling one's own personal dictionary.-J.S.

The Foundation Center has revised several of its publications. The National Guide to Funding in Arts and Cultures by Elizabeth H. Rich is in its fifth edition (New York: Foundation Center, 1998. 1409p. \$145 paper) and gives information for 4,618 grant-making foundations, 342 direct corporate-giving programs, 277 public charities, and 1,100 descriptions of recently awarded grants. Especially enriched is the index with more subject and geographical terms. In the revision of the Foundation Center's Guide to Proposal Writing by Jane C. Geever (New York: 1997.213p. \$20 paper; 1st ed. 1993), there is an interesting section on what should go into the proposal. 
Joseph Gibaldi has revised the MLA Style Manual and Guide to Scholarly Publishing (New York: Modern Language Association, 1998. 343p. \$25.00; 1st ed. 1985, comp. Walter Achert and Gibaldi, Guide AA317) to "establish ground rules and provide practical advice for scholars-from advanced undergraduates to authors preparing their first book for publication. Of especial interest are the chapters on legal issues in scholarly publishing, citing electronic publications, standard abbreviations. The MLA Handbook for Writers of Research Papers, also by Gibaldi ( $4^{\text {th }}$ ed. 1997. 293p. $\$ 20.00$ paper), is intended primarily for undergraduates.

Another style manual received revision: Where Credit Is Due: A Guide to Proper Citing of Sources, Print and Nonprint by Nancy E. Shields (Lanham, Md.: Scarecrow, 1997. 189p. \$32.50; 1st ed. 1985. $252 p$ ) is addressed to the beginning student. It includes information on citing nonprint material such as microscope slides, radio broadcasts, telephone/conference calls. There also is a glossary of terms in common use today, such as Internet, URL, reel to reel, slash, and a list of standard abbreviations.

British Directories: A Bibliography and Guide to Directories Published in England and Wales (1850-1950) and Scotland (17731950), compiled by Gareth Shaw and Allison Tipper, is in a second edition (New York: Mansell, 1997. 459p. il., maps \$150) (see Guide AL1 for details on the first edition, 1989, and also on its relationship to other bibliographies of British directories). This bibliography adds directories of specific trades, provides comprehensive coverage of all Scottish directories prior to 1950, reports holdings of 120 library collections that have been visited, and offers revised indexes arranged by publisher, place, and subject. There is a new chapter on the use of directory material in historical studies and a list of corrections and additions received since the first edition. Shaw and Tim Coles have begun a new work, Guide to European Town Directories, following the same pattern (Aldershot, Hants Brookfield, Vt.:
Ashgate). Volume one covers towns in Germany, Austria, Switzerland, and the Scandinavian countries (1997. 327p. \$93.95), and volume two will focus on France, the Low Countries, Italy, Portugal, and Spain.

The third edition of Literary Research Guide: An Annotated Listing of Reference Sources in English Literary Studies, by James L. Harner, maintains the same wealth of information (New York: MLA, 1998. \$19.75; 2d ed. 1993, Guide BE396, formerly subtitled A Guide to Reference Sources for the Study of Literatures in English and Related Topics) and has "deleted 47 entries, added 60, revised 560 resulting in an edition that includes 1,027 entries, refers to 1,331 additional books, articles and electronic resources in annotations and headnotes and cites 752 reviews" (Pref. to 3rd ed.). Harner goes on to say that although he has cited "URLs for Internet sites related to printed works, databases and online library catalogs. I have admitted a few resources that exist only as World Wide Web sites. As I write (April 1997) the Web is too unstructured, unregulated and unstable to offer many library reference sources of value." He does, however, offer his own Web site for revisions and additions: http://www. english.tamu.edu/pubs/lrg.

The Wing Short Title Catalogue of Books Printed in England, Scotland, Ireland, Wales and British America and of English Books Printed in Other Countries (New York: MLA, 1972-1998. 4v. Guide AA683) is now complete with the publication of volume four, Indexes (1998. 1078p. \$250). This provides the "Index of Printers, Publishers, and Booksellers," and a "Chronological Index of Non-London Publications." The headnotes for the printers were complied by Carolyn W. Nelson and Malcolm Seccombe and are, in many cases, very brief (e.g., dates and address, but with a reference to the source). The printer's name is followed by a chronological listing of titles of works with Wing numbers.

Covering from "A Band Apart Productions" to "Zoom Lens," Anthony Slide has updated his American Film Industry (1988. 
Guide $\mathrm{BH} 254)$ and retitled it New Historical Dictionary of the American Film Industry (Lanham, Md.: Scarecrow, 1998. 266p. \$55). Featuring about 200 new entries (e.g., Agents, Akeley Pancake Camera, Body Building in the Cinema, Alcoholism), he has dropped some (e.g., animation, Academy of Science Fiction, Fantasy and Horror Films) and revised others (e.g. Blacks in American film, Columbia Pictures). The entries still feature short bibliographies and references to primary resources that now include holdings of several additional libraries.

Louise Spain's Dance on Camera: A Guide to Dance Films and Videos (Lanhan, Md. : Scarecrow, 1998. 238p. \$65) is the revised edition of Dance Film and Video Guide by Deirdre Towers (1991. Guide BH149) and offers a title listing of 1,400 films giving information such as credits, source, abstract, and distributors. The index adds awards, categories, excerpts, and series titles.

Volume One of Medieval Scholarship: Biographical Studies of the Formation of a Discipline (1995) covered historians from the seventeenth to the twentieth centuries. Volume Two (New York: Garland, 1998. 465p. \$95. Garland Reference Library of the Humanities 2071), edited by Helen Damico, "provides thirty-two accounts of men and women from the 16th century to the $20^{\text {th }}$ who developed medieval philology and literature into a profession" (Pref.). Essays cover figures such as the Grimm brothers, C. S. Lewis, Rosemary Woolf, and Ramon Menendez Pidal, and also includes a selective primary and secondary bibliography. The volume ends with a good subject index. Volume three will deal with scholars of medieval philosophy, art, and music.

Who's Who in British History appeared in volumes covering certain periods, such as Roman, Anglo-Saxon, Late Medieval, Early Hanoverian (1988-1997. Guide DC298). These have all been merged into one alphabet, Who's Who in British History: Beginnings to 1901, Geoffrey Treasure, general editor (London, Chicago: Fitzroy Dearborn, 1998. 2v. 1392p. \$270.00), but with a chronological list of entries. Also, there are indexes by name and by category, for example, philosophers, politicians and royal advisors, newspaper proprietors and publishers, religious women, sports and games figures. Further reading concludes each entry, and there is a general reading list by period.

According to the preface of the Dictionary of Irish Biography by Henry Boylan, the third edition (Dublin: Gill \& Macmillan, 1998. 461p \$35.; 2d ed. 1988, Guide AH255) corrects minor errors from the earlier edition and adds new entries. The "work has been completely redesigned and reformatted and is illustrated for the first time."

Pan-African Chronology: A Comprehensive Reference to the Black Quest for Freedom in Africa, the Americas, Europe and Asia, compiled by Everett Jenkins (1996) covered the period from 1400 to 1865 . Jenkins has extended the dates with Pan-African Chronology II for 1865 to 1915 (Jefferson, N.C.: McFarland, 1998. 572p. \$65).

The New Encyclopedia of the American West, edited by Howard R. Lamar (New Haven, Conn.: Yale Univ. Pr., 1998. 1324p. $\$ 60)$ is a revision of Lamar's Reader's Encyclopedia of the American West (1977. Guide DB174). The number of contributors has grown to about 300 , more individuals are treated, especially writers, the bibliographies and statistics are updated, and there is a new index by name of person. Also new is the Timeline of the American West 40,000 BC-1998.

Herman C. Kemp has expanded his Annotated Bibliography of Bibliographies on Indonesia (1990. Guide AA78) to include all the countries of Southeast Asia, Bibliographies on Southeast Asia (Leiden: KITLV Pr., 1998. 1128p. \$126.50. Bibliographical Series 22), with good coverage through 1996 and a few entries from 1997. The 5,380 entries are arranged by subject, and the volume concludes with author/subject/title indexes.

Finally, the new edition of the gazetteer has arrived: Columbia Gazetteer of the World, edited by Saul B. Cohen (New York: Columbia Univ. Pr., 1998. 3v. 3578p. \$750), formerly called Columbia Lippincott 
Gazetteer of the World (1962. Guide CL85) because it was based on Lippincott's Pronouncing Gazetteer (1855, rev. 1905). Five years in the making, almost every entry has been changed and there are 3,000 new ones. The United States is well covered with 40,000 entries for every incorporated and many unincorporated places, every county, some special-purpose sites, and physical features. But other areas of the world are thoroughly addressed (e.g., 6,048 entries for Russia, 2,007 for Greece, 69 for Malta). The information given is very full with much reliance on official sources. As is true of the earlier edition, there are no maps. An electronic version is planned for fal1 of 1999.

Ny litteratur om kvinnor, the international women's studies bibliography from Gothenburg University Library, is available as a free database: KVINNSAM (http: / / www.libris.kb.se/english / special.database.DAKS.html) and supersedes the printed volumes from 1981 to the present, with more than 60,000 references books, journals, journal articles, book chapters, scholarly papers, booklets, and research reports.-S.S.W. 